\title{
Exploration of the structural features and magnetic behaviour in a novel 3-dimensional interpenetrating $\mathrm{Co}$ (II)-based framework
}

\author{
SOUMYABRATA GOSWAMI, AMIT KUMAR MONDAL and SANJIT KONAR* \\ Department of Chemistry, IISER Bhopal, Indore By-pass Road, Bhauri, Bhopal 462 066, India \\ e-mail: skonar@iiserb.ac.in
}

MS received 29 September 2014; accepted 9 October 2014

\begin{abstract}
A new Co(II)-based three-dimensional (3D) framework having the molecular formula $\left[\mathrm{Co}\left(\mathrm{C}_{4} \mathrm{O}_{4}\right)\right.$ $\left.\left.(4-b p m h)) \mathrm{H}_{2} \mathrm{O}\right)_{2}\right]_{\mathrm{n}} \cdot 2 \mathrm{nH}_{2} \mathrm{O} \cdot 2 \mathrm{nMeOH} \cdot(\mathbf{1})(4-\mathrm{bpmh}=\mathrm{N}$, N-bis-pyridin-4-ylmethylene-hydrazine) has been synthesized using a mixed ligand system and characterized by elemental analysis, IR spectroscopy, thermogravimetric analysis, single crystal $\mathrm{X}$-ray diffraction and variable temperature magnetic study. The framework is constructed by the bridging squarate $\left(\mathrm{C}_{4} \mathrm{O}_{4}^{2-}\right)$ and $\mathrm{N}$, N-bis-pyridin-4-ylmethylene-hydrazine (4-bpmh) ligands and interpenetration of the 2D grid-like frameworks at definite angles gives rise to $2 \mathrm{D} \rightarrow 3 \mathrm{D}$ inclined polycatenation with sql/Shubnikov tetragonal plane net topology. Extensive non-covalent interactions (H-bonding as well as $\pi \cdots \pi$ interactions) are also observed which stabilises the 3D arrangement. Additionally, complex $\mathbf{1}$ contains 1D channels of large dimensions $\left(10.91 \times 11.78 \AA^{2}\right)$ that runs along the $b$-axis. Variable temperature DC magnetic susceptibility study reveals dominant spin-orbit coupling effect typical of the ${ }^{4} \mathrm{~T}_{1 \mathrm{~g}}$ ground state of octahedral high-spin Co(II) ion at a higher temperature range.
\end{abstract}

Keywords. Mixed ligand system; Co(II)-based 3D framework; interpenetrated structure; sql/Shubnikov tetragonal plane net topology; non-covalent interactions; magnetic studies.

\section{Introduction}

Research on metal-organic frameworks (MOFs) has received immense importance in the past few decades owing to their fundamentally endless number of possible structures with variable interesting properties such as gas storage and separation, ${ }^{1}$ molecular magnetism, ${ }^{2}$ catalysis, ${ }^{3}$ drug delivery, ${ }^{4}$ luminescence, ${ }^{5}$ etc. The architectural topology in MOFs is a very vital parameter and regulates its properties and applications. Therefore, many interesting structural features and their related properties have been investigated in detail. ${ }^{6}$ Literature survey reveals that the structures in the MOFs and their properties are governed by various factors like geometric requirements of metal atoms, structure of connecting ligands, metal to ligand ratio, etc. ${ }^{7}$ Among these factors, choice of spacers is utmost important, because even small changes in them can lead to remarkable diversity in structure and properties. $^{8}$ Very promising approach in this regards is the use of mixed ligands such as polycarboxylate and $\mathrm{N}$-containing multipyridyl bridging ligands in the same system. ${ }^{9}$ Bis-pyridyl ligands such as N,N-bispyridin-4-ylmethylene-hydrazine (4-bpmh), N, N-bis-

\footnotetext{
*For correspondence
}

pyridin-3-ylmethylene-hydrazine(3-bpmh) have conformational flexibility which justifies their versatility as organic building blocks for the construction of coordination architectures. ${ }^{10}$ On the other hand, small carboxylic acid ligands like deltic acid, squaric acid, croconic acid, etc. are highly efficient to mediate strong magnetic interactions among the metal centres and render the MOFs magnetically potent. In ourpresent work, we successfully applied this strategy and obtained a new MOF formulated as $\left[\mathrm{Co}\left(\mathrm{C}_{4} \mathrm{O}_{4}\right)(4-\right.$ bpmh)) $\left.\left.\mathrm{H}_{2} \mathrm{O}\right)_{2}\right]_{\mathrm{n}} \cdot 2 \mathrm{nH}_{2} \mathrm{O} \cdot 2 \mathrm{nMeOH} \cdot(\mathbf{1})$. Their synthesis, crystal structures, topologies, thermal stabilities, and magnetic properties are reported in this paper.

\section{Experimental}

\subsection{Materials}

All the reagents and solvents were commercially available and were used as obtained. Squaric acid, lithium carbonate, and $\mathrm{Co}\left(\mathrm{ClO}_{4}\right)_{2} \cdot 6 \mathrm{H}_{2} \mathrm{O}$ were obtained from the Sigma Aldrich Chemical Co. Dilithium squarate was prepared by dissolving lithium carbonate and squaric acid in water in a 1:1 molar ratio, stirring for a few hours, and finally evaporating the solvent to get a white coloured solid compound. 
Caution! Perchlorate salts are potentially hazardous, and caution should be exercised when dealing with such salts.

\subsection{Synthesis of 4-bpmh}

The ligand 4-bpmh was synthesised following the previously known procedure. ${ }^{10 \mathrm{~g} 1} \mathrm{H}$ NMR $(400 \mathrm{MHz}$, $\left.\mathrm{CDCl}_{3}\right): \delta 7.66(4 \mathrm{H}, \mathrm{d}, \mathrm{J}=4.07 \mathrm{~Hz}), 8.52(2 \mathrm{H}, \mathrm{s}, \mathrm{J}=$ $1.98 \mathrm{~Hz}), 8.72(4 \mathrm{H}, \mathrm{d}, \mathrm{J}=4.00 \mathrm{~Hz}) \cdot{ }^{13} \mathrm{C} \mathrm{NMR}(400$ $\left.\mathrm{MHz}, \mathrm{CDCl}_{3}\right): \delta=160.62,150.70,140.83,122.36$ (figures $\mathrm{S} 1$ and $\mathrm{S} 2$ ).

\subsection{Synthesis of $\left[\mathrm{Co}\left(\mathrm{C}_{4} \mathrm{O}_{4}\right)(4-b p m h)\left(\mathrm{H}_{2} \mathrm{O}\right)_{2}\right]_{n}$. $2 \mathrm{nH}_{2} \mathrm{O} \cdot 2 \mathrm{nMeOH} \cdot(1)$}

Li-squarate (1.5 mmol, $171 \mathrm{mg})$ was taken in $15 \mathrm{~mL}$ of water and stirred for $20 \mathrm{~min}$ to dissolve. $\mathrm{Co}\left(\mathrm{ClO}_{4}\right)_{2} \cdot 6 \mathrm{H}_{2} \mathrm{O}(0.3 \mathrm{mmol}, 109 \mathrm{mg})$ and 4-bpmh $(0.3$ mmol, $63 \mathrm{mg}$ ) were dissolved in $3 \mathrm{~mL}$ of methanol, and this solution was slowly and carefully layered over $3 \mathrm{~mL}$ of the aqueous solution of Li-squarate, using $2 \mathrm{~mL}$ of a 1:1 mixture of water and methanol as a third middle layer to slow down the diffusion, in a narrow glass tube. Pink coloured rhombus-shaped crystals were formed after few days in the tube (scheme 1). The crystals were separated, washed with cold water and $\mathrm{Et}_{2} \mathrm{O}$, and air dried (yield 68\%). Anal. Calcd. for $\mathrm{C}_{18} \mathrm{H}_{24} \mathrm{CoN}_{4} \mathrm{O}_{10}$ : C, 41.95; $\mathrm{H}, 4.69 ; \mathrm{N}, 10.87 \%$. Found: C, 42.02; H, 4.88; N, 10.95\%. FT-IR ( $\mathrm{KBr}$ pellet, $\left.4000-400 \mathrm{~cm}^{-1}\right)$ : 638s, 822s, 972w, 1082vs, 1285vs, 1310w, 1364s, 1420vs, 1490w, 1521vs (C-C and $\mathrm{C}-\mathrm{O}), 1542 \mathrm{~s}, 1625 \mathrm{vs}(\mathrm{C}=\mathrm{N}), 3061 \mathrm{~m}, 3433(\mathrm{O}-\mathrm{H})$ (figure S3).

\subsection{Physical measurements}

The elemental analyses were carried out on Elementar Microvario Cube Elemental Analyzer. FT-IR spectra (4000-400 $\mathrm{cm}-1$ ) were recorded on $\mathrm{KBr}$ pellets with a Perkin-Elmer Spectrum BXspectrometer. Powder Xray diffraction (PXRD) data were collected on a PANalytical EMPYREAN instrument using $\mathrm{Cu}-\mathrm{K} \alpha$ radiation. Magnetic measurements were performed using a Quantum Design SQUID VSM magnetometer. The measured values were corrected for the experimentally measured contribution of the sample holder, while the derived susceptibilities were corrected for the diamagnetism of the samples, estimated from Pascal's tables. ${ }^{2 b}$

\section{$2.5 X$-ray crystallography}

Single crystal X-ray data collection of the complexes was performed at $296 \mathrm{~K}$ on a Brüker Smart Apex-II CCD diffractometer with graphite monochromated Mo$\mathrm{K} \alpha(\lambda=0.71073 \AA)$ radiation. Data collections were performed using $\varphi$ and $\omega$ scans. The structures were solved using direct methods followed by full matrix least-squares refinements against $\mathrm{F}^{2}$ (all data HKLF 4 format) using SHELXTL. ${ }^{11}$ A multiscan absorption correction, based on equivalent reflections, was applied to the data. Anisotropic refinement was used for all nonhydrogen atoms. Hydrogen atoms were placed in appropriate calculated positions. During the final stages of refinement, several Q peaks were found, which probably correspond to highly disordered solvent molecules and are removed by SQUEEZE ${ }^{12}$ programme. From the TG analysis (figure S4), it is confirmed that two non-coordinated $\mathrm{H}_{2} \mathrm{O}$ and two non-coordinated $\mathrm{CH}_{3} \mathrm{OH}$ molecules are present (calcd. 19.4\%; found $20.1 \%$ ) and, hence, these are included in the molecular formula and accordingly, the molecular weights have been corrected and mentioned in the crystallographic table (table 1). $\mathrm{X}$-ray crystallographic data in CIF format are available in CCDC number 1026263.

\section{Results and Discussion}

\subsection{Structural description of complex 1}

Complex 1 crystallizes in monoclinic system with a $C 2 / c$ space group. The basic molecular unit contains one $\mathrm{Co}$ (II) ion, one squarate ligand, one 4-bpmhlinker and two water molecules (figure 1). Each Co(II) centre acquires regular octahedral geometry and is ligated by two nitrogen atoms from two different 4-bpmh ligands, two oxygen atoms from two squarate ligands and two oxygen atoms from two water molecules. The $\mathrm{Co}-\mathrm{O}$ bond lengths are 2.105(2) $\AA$, Co-N bond lengths are 2.165(2) $\AA$ and bond angles around the Co(II) centre are

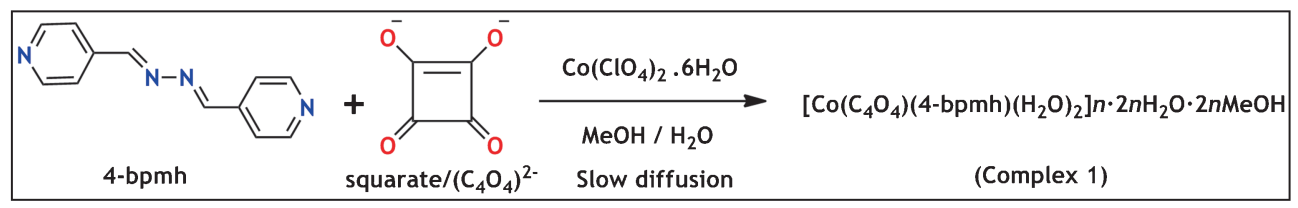

Scheme 1. Schematic representation of the synthesis of complex $\mathbf{1}$. 
Table 1. X-ray crystallographic data and refinement parameters for complex $\mathbf{1}$.

\begin{tabular}{|c|c|}
\hline & 1 \\
\hline Formula & $\mathrm{C}_{18} \mathrm{H}_{24} \mathrm{CoN}_{4} \mathrm{O}_{10}$ \\
\hline $\mathrm{M}_{\mathrm{w}}\left(\mathrm{g} \mathrm{mol}^{-1}\right)$ & 515.34 \\
\hline Crystal size (mm) & $0.40 \times 0.34 \times 0.28$ \\
\hline Crystal system & Monoclinic \\
\hline Space group & $\mathrm{C} 2 / \mathrm{c}$ \\
\hline $\mathrm{T}(\mathrm{K})$ & $296(2)$ \\
\hline $\mathrm{a}(\AA)$ & $26.509(17)$ \\
\hline b $(\AA)$ & 11.734(6) \\
\hline c $(\AA)$ & $7.955(4)$ \\
\hline$\alpha\left(^{\circ}\right)$ & 90.00 \\
\hline$\beta\left(^{\circ}\right)$ & $97.350(11)$ \\
\hline$\gamma\left({ }^{\circ}\right)$ & 90.00 \\
\hline $\mathrm{V}\left(\AA^{3}\right)$ & 2454(2) \\
\hline Z & 4 \\
\hline$\rho_{\text {calcd }}\left(\mathrm{g} \mathrm{cm}^{-3}\right)$ & 1.124 \\
\hline$\mu(\mathrm{MoK} \alpha)\left(\mathrm{mm}^{-1}\right)$ & 0.729 \\
\hline$F(000)$ & 844.0 \\
\hline$T_{\max }, T_{\min }$ & $0.815,0.747$ \\
\hline$h, k, l$ range & $-35 \leq h \leq 35,-15 \leq k \leq 15,-9 \leq l \leq 10$ \\
\hline Collected reflections & 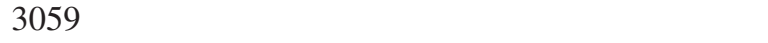 \\
\hline Independent reflections & 1834 \\
\hline Goodness-of-fit (GOF) on $\mathrm{F}^{2}$ & 0.956 \\
\hline $\mathrm{R} 1, \mathrm{wR} 2(\mathrm{I}>2 \sigma \mathrm{I})$ & $0.0465,0.1203$ \\
\hline R1, wR2 (all data) & $0.0803,0.1313$ \\
\hline CCDC Number & 1026263 \\
\hline
\end{tabular}

$\mathrm{R} 1=\Sigma\left\|\mathrm{F}_{\mathrm{o}}|-| \mathrm{F}_{\mathrm{c}}\right\| / \Sigma\left|\mathrm{F}_{\mathrm{o}}\right| \& \mathrm{wR} 2=\left|\Sigma \mathrm{w}\left(\left|\mathrm{F}_{\mathrm{o}}\right|^{2}-\left|\mathrm{F}_{\mathrm{c}}\right|^{2}\right)\right| / \Sigma\left|\mathrm{w}\left(\mathrm{F}_{\mathrm{o}}\right)^{2}\right|^{1 / 2}$.

found in the range of 88.05(8)-94.30(8) ${ }^{\circ}$ (table 2). The $\mathrm{Co}(\mathrm{II}) \cdots \mathrm{Co}$ (II) distances bridged by squarate $\left(\mu_{1,3^{-}}\right.$ bridging) and 4-bpmh ligands are 7.95 and $15.69 \AA$, respectively.

The $\mathrm{Co}(\mathrm{II})$ ions in $\mathbf{1}$ are arranged in onedimensional (1D) fashion along the $b$-and $c$-axes through anti-anti $\mu_{1,3}-\mathrm{O}$ bridged squarate ions. These 1D chains are linked through bridging 4-bpmh ligands to form a two-dimensional (2D) rhombohedral grid-like framework (figure 2) along the $a c$ and $a b$ planes. The 2D sheets are actually made up of infinite array of metallocycles (figure 2) formed by four $\mathrm{Co}(\mathrm{II})$ centres, two squarate ligands and two 4-bpmh ligands, with a dimension of $7.95 \times 15.69 \AA^{2}$. These large voids inevitably resulted in an interpenetrated structure which is revealed from TOPOS software ${ }^{13}$ analysis.

From further structural investigation, it is observed that the 2D sheets (figure 3a) are related to each other through polycatenation, ${ }^{14}$ giving rise to a parallel/parallel inclined interpenetration (figure 3b), and the overall three-dimensional (3D) framework is formed by two sets of inclined interpenetrated planes with a
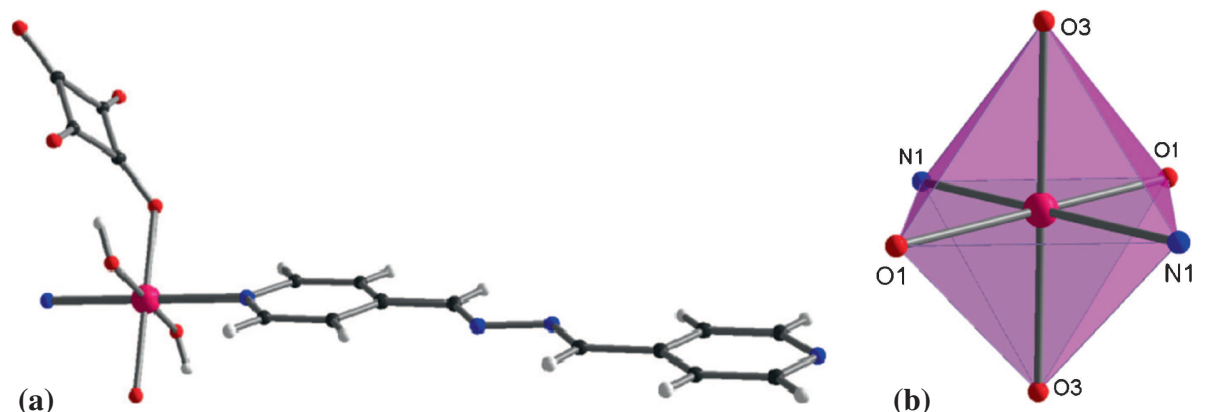

Figure 1. (a) View of the basic molecular unit of complex 1. Colour codes: Magenta-Co, gray-C, red-O, blue-N, light gray-H; (b) Polyhedral view of the coordination environment around the $\mathrm{Co}(\mathrm{II})$ ion. 
Table 2. Bond distances $(\AA)$ and bond angles $\left(^{\circ}\right)$ around Co(II) found in complex $\mathbf{1}$.

\begin{tabular}{|c|c|c|c|c|c|}
\hline \multicolumn{2}{|c|}{ Bond lengths $(\AA)$} & \multicolumn{4}{|c|}{ Bond angles $\left(^{\circ}\right)$} \\
\hline Co1 - O1 & $2.105(2)$ & $\mathrm{O} 1-\mathrm{Co} 1-\mathrm{O} 3$ & $85.70(8)$ & $\mathrm{N} 1-\mathrm{Co} 1-\mathrm{O} 3 \mathrm{~A}$ & $91.09(9)$ \\
\hline $\mathrm{Co} 1-\mathrm{O} 3$ & $2.105(2)$ & $\mathrm{O} 1-\mathrm{Co} 1-\mathrm{O} 3 \mathrm{~A}$ & $94.30(8)$ & $\mathrm{N} 1 \mathrm{~A}-\mathrm{Co} 1-\mathrm{O} 3 \mathrm{~A}$ & 88.91(9) \\
\hline $\mathrm{Co} 1-\mathrm{N} 1$ & $2.165(2)$ & $\mathrm{O} 1 \mathrm{~A}-\mathrm{Co} 1-\mathrm{O} 3$ & $94.30(8)$ & $\mathrm{O} 1-\mathrm{Co} 1-\mathrm{N} 1$ & $88.05(8)$ \\
\hline Co1 - O1A & $2.105(2)$ & $\mathrm{O} 1-\mathrm{Co} 1-\mathrm{O} 3 \mathrm{~A}$ & $85.70(8)$ & $\mathrm{O} 1-\mathrm{Co} 1-\mathrm{N} 1 \mathrm{~A}$ & $91.95(8)$ \\
\hline Co1 - O1A & $2.105(2)$ & $\mathrm{N} 1-\mathrm{Co} 1-\mathrm{O} 3$ & $88.91(9)$ & $\mathrm{O} 1 \mathrm{~A}-\mathrm{Co} 1-\mathrm{N} 1$ & $91.95(8)$ \\
\hline $\mathrm{Co} 1-\mathrm{N} 1 \mathrm{~A}$ & $2.165(2)$ & $\mathrm{N} 1 \mathrm{~A}-\mathrm{Co} 1-\mathrm{O} 3$ & $91.09(9)$ & $\mathrm{O} 1 \mathrm{~A}-\mathrm{Co} 1-\mathrm{N} 1 \mathrm{~A}$ & $88.05(8)$ \\
\hline
\end{tabular}

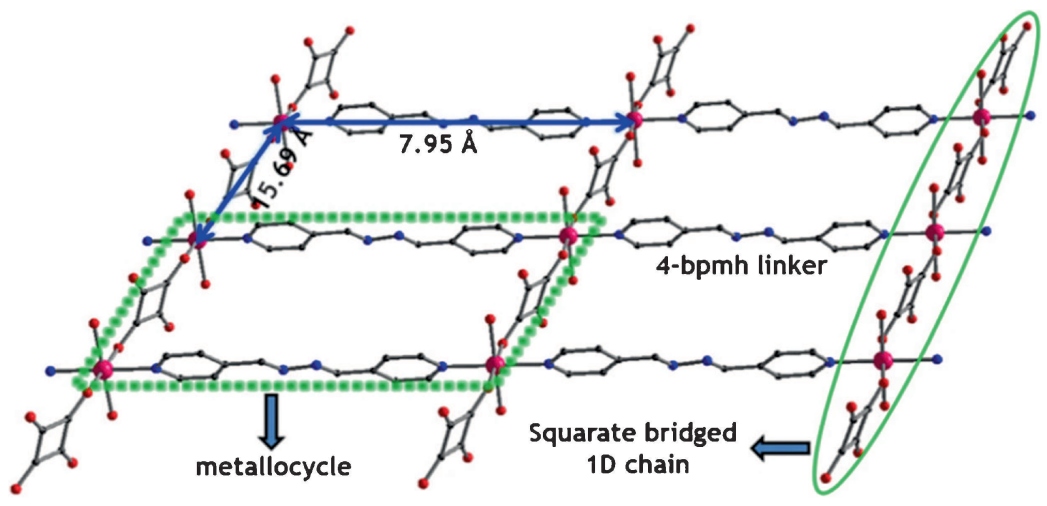

Figure 2. Illustration of the $2 \mathrm{D}$ rhombohedral grid framework formed by the squarate bridged 1D chains and the 4-bpmh linker and the metallocycle. $\mathrm{H}$ atoms have been omitted for clarity.

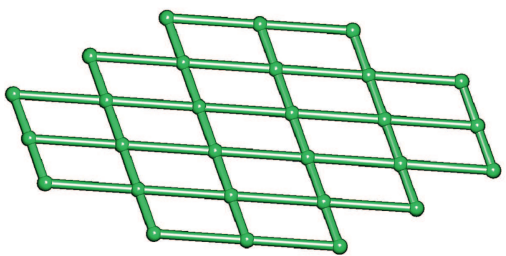

(a)

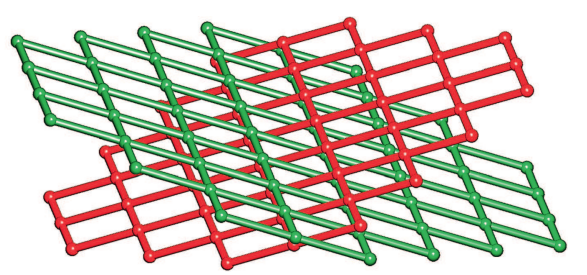

(b)

Figure 3. (a) View of a 2D sheet formed by metal centres (solid balls) and bridging squarate and 4-bpmh ligands (solid rods) in 1. (b) View of the 2D+2D inclined interpenetrated network. The two different sets of parallel planes are shown in green and red for clarity.

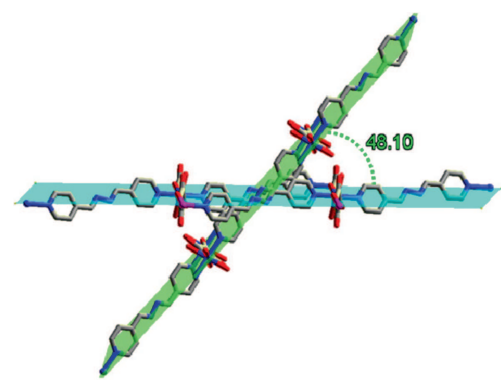

(a)

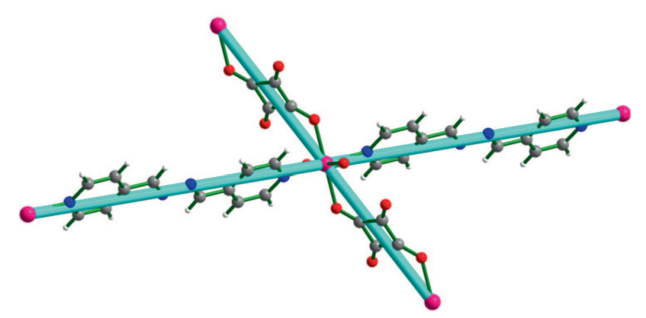

(b)

Figure 4. (a) Illustration of dihedral angle between two sets of inclined interpenetrated planes; (b) Representation of the 4-connected node. 
dihedral angle of $48^{\circ}$ (figure 4a). Hence, complex 1 represents a 4-connected uninodal (figure $4 b$ ) framework with sql/Shubnikov tetragonal plane net topology and point Schälfli symbol $\left\{4^{4} \cdot 6^{2}\right\}$.

The 3D framework also features 1D channels of dimensions about $10.91 \times 11.78 \AA^{2}$ running along the $b$-axis (figure 5) and non-coordinated water and methanol molecules occupy the free void spaces in the channels. Calculation of the void volume for the complex 1 by PLATON analysis ${ }^{15}$ revealed pore-accessible volume of $36.1 \%$ with respect to the whole unit cell volume ( 884.8 out of $2454.0 \AA^{3}$ per unit cell volume). The intricate $3 \mathrm{D}$ structural architecture is also stabilised by both H-bonding (table 3 ) as well as $\pi \cdots \pi$ interaction $\left(\pi_{\mathrm{C}=\mathrm{N}} \cdots \pi_{\mathrm{C}=\mathrm{N}}\right)$ with centroid-to-centroid distance of $3.51 \AA$ (figure 6 ).

\subsection{Magnetic studies of complex $\mathbf{I}$}

The purity of the as-synthesized product was indicated by the good agreement of the bulk phase powder $\mathrm{X}$-ray diffraction patterns with the one simulated on the basis of the single crystal structure data (figure S5). The powder was used for magnetic property measurements. Variable temperature magnetic susceptibility data of a powder sample of $\mathbf{1}$ was measured in the temperature range of 1.8-300 $\mathrm{K}$ under an applied field of $0.1 \mathrm{~T}$ and is shown in figure 7 in the form of $\chi_{M} T v s$. $T$. At $300 \mathrm{~K}$, a $\chi_{M} T\left(\chi_{M}=\right.$ molar magnetic susceptibility) value of $2.95 \mathrm{~cm}^{3} \mathrm{~mol}^{-1} \mathrm{~K}$ is obtained, which is higher than the spin only value of $1.875 \mathrm{~cm}^{3} \mathrm{~mol}^{-1} \mathrm{~K}$ for a high spin $\mathrm{Co}$ (II) ion. This is due to unquenched

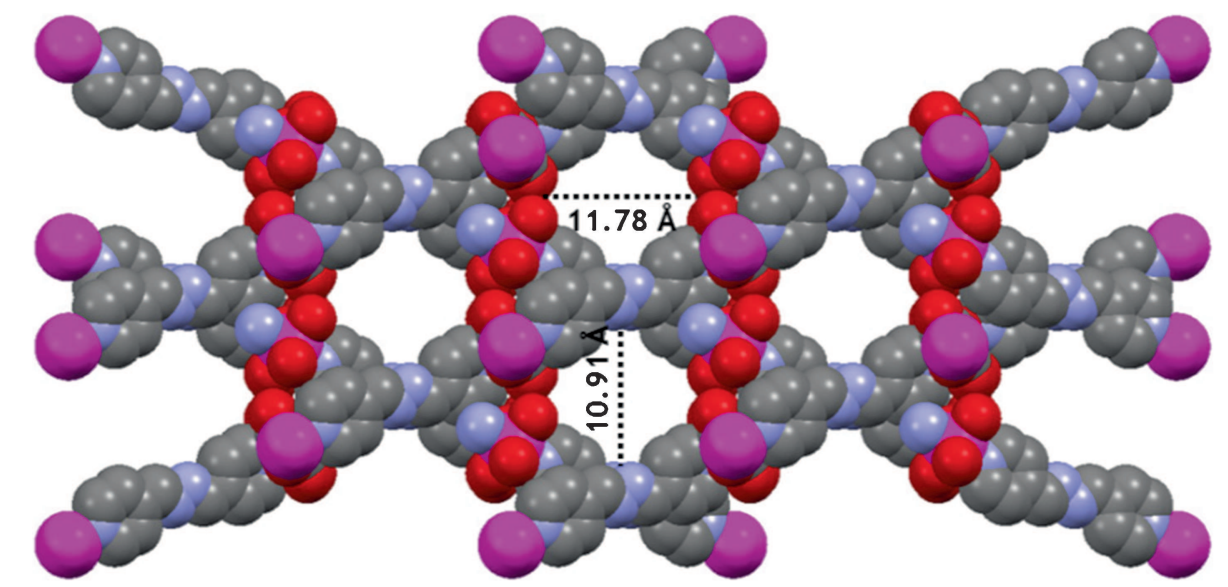

Figure 5. View of $1 \mathrm{D}$ channels of dimensions about $10.91 \times 11.78 \AA^{2}$ running along the $b$-axis.

Table 3. H-bond parameters found in complex $\mathbf{1}$.

\begin{tabular}{|c|c|c|c|c|c|}
\hline $\mathrm{D}-\mathrm{H} \cdots \mathrm{A}$ & D-H $(\AA)$ & $\mathrm{H} \cdots \mathrm{A}(\AA)$ & $\mathrm{D} \cdots \mathrm{A}(\AA)$ & $<\mathrm{D}-\mathrm{H}-\mathrm{A}\left(^{\circ}\right)$ & Symmetry \\
\hline $\mathrm{C} 3-\mathrm{H} 3 \mathrm{~A} \cdots \mathrm{O} 3$ & 1.080 & 2.642 & $3.143(4)$ & 107.72 & 0 \\
\hline $\mathrm{C} 4-\mathrm{H} 4 \cdots \mathrm{N} 2$ & 1.080 & 2.553 & $2.845(4)$ & 94.26 & 0 \\
\hline $\mathrm{O} 3-\mathrm{H} 3 \cdots \mathrm{O} 2$ & 0.938 & 1.759 & $2.677(3)$ & 165.19 & 1 \\
\hline $\mathrm{C} 7-\mathrm{H} 7 \cdots \mathrm{O} 2$ & 1.080 & 2.526 & $3.586(4)$ & 167.00 & 2 \\
\hline
\end{tabular}

\#(0)x,y,z; (1) x, +y, $+\mathrm{z}+1 ;(2)-\mathrm{x}+1 / 2,+\mathrm{y}-1 / 2,-\mathrm{z}+1 / 2+1$.
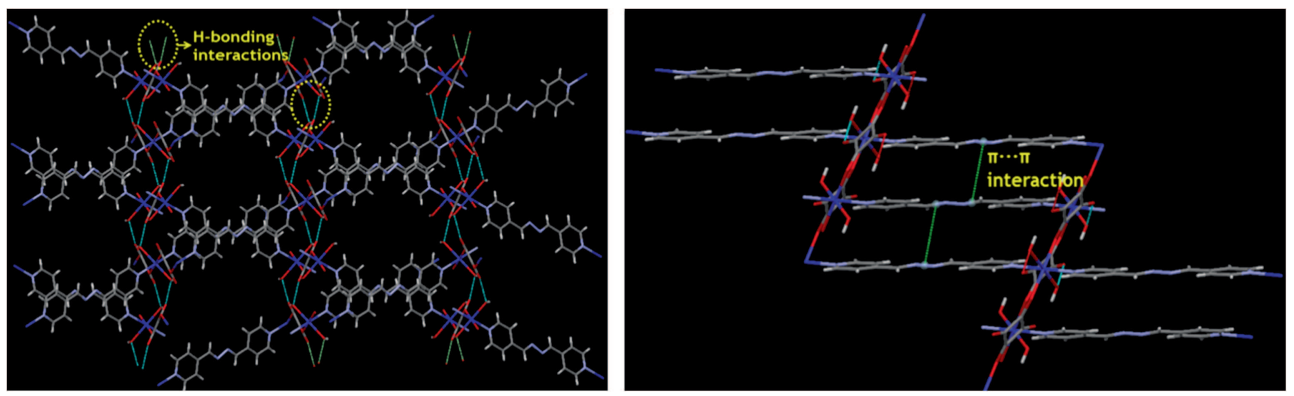

Figure 6. Illustration of H-bonding interaction (left) and $\pi \cdots \pi$ interaction (right) stabilising the 3D framework. 


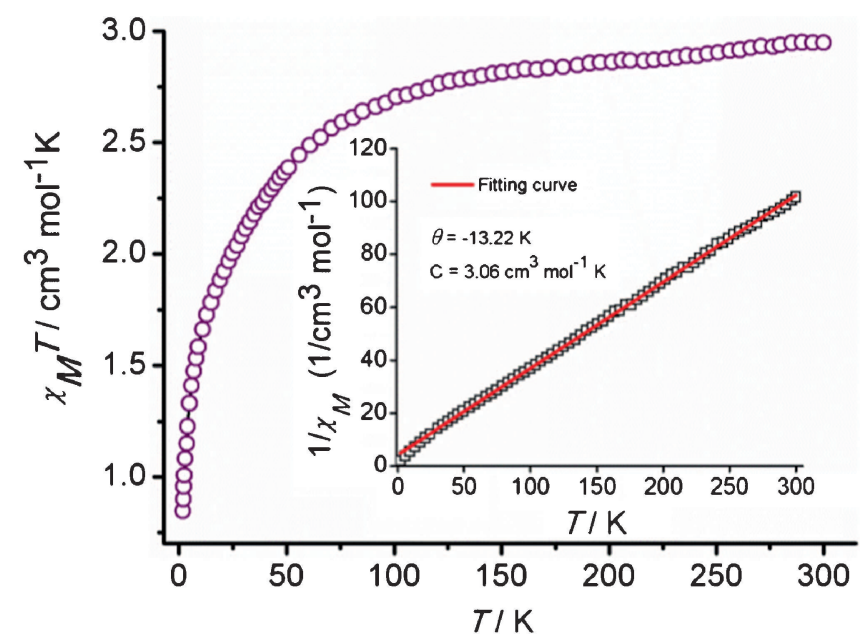

Figure 7. $\chi_{M} T$ vs. $T$ plot for complex 1 measured at $0.1 T$. Inset graph shows inverse susceptibility curve and its CurieWeiss fitting (red line).

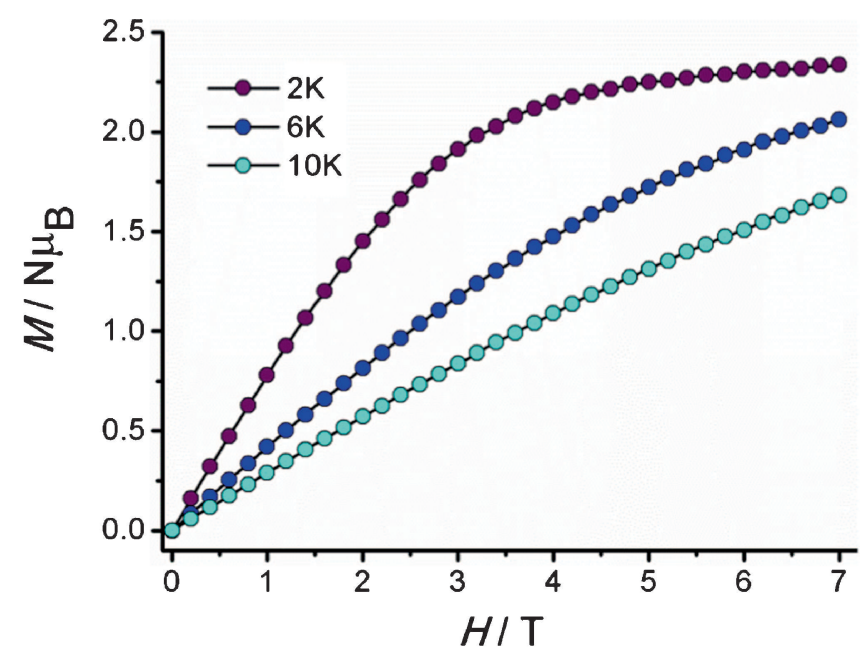

Figure 8. Isothermal magnetization curves for $\mathbf{1}$ at 2,6 and at $10 \mathrm{~K}$.

orbital-moment as a consequence of spin-orbit coupling typical of the ${ }^{4} \mathrm{~T}_{1 \mathrm{~g}}$ ground state of octahedral high-spin Co(II) ion. ${ }^{16}$ Upon lowering the temperature, $\chi_{M} T$ continuously decreases and reaches a minimum of $0.83 \mathrm{~cm}^{3} \mathrm{~mol}^{-1} \mathrm{~K}$ at $1.8 \mathrm{~K}$. This feature of decrease in the $\chi_{M} T$ value upon cooling is due to the depopulation of the excited Kramer's levels ascribed to the splitting of ${ }^{4} \mathrm{~T}_{1 \mathrm{~g}}$ ground states under crystal field effects and spin-orbital coupling. ${ }^{16}$

$1 / \chi_{M}$ data for complex 1 within the temperature range of $1.8-300 \mathrm{~K}$, was fitted according to the CurieWeiss equation, $\left[\chi_{M}=\mathrm{C} /(\mathrm{T}-\theta)\right]$, which afforded the Curie constant, $\mathrm{C}=3.06 \mathrm{~cm}^{3} \mathrm{~mol}^{-1} \mathrm{~K}$, and Weiss temperature, $\theta=-13.22 \mathrm{~K}$ (figure 7 inset). The negative $\theta$ value indicates the spin orbit coupling effects of single $\mathrm{Co}(\mathrm{II})^{15}$ ion in higher-temperature range and, therefore,

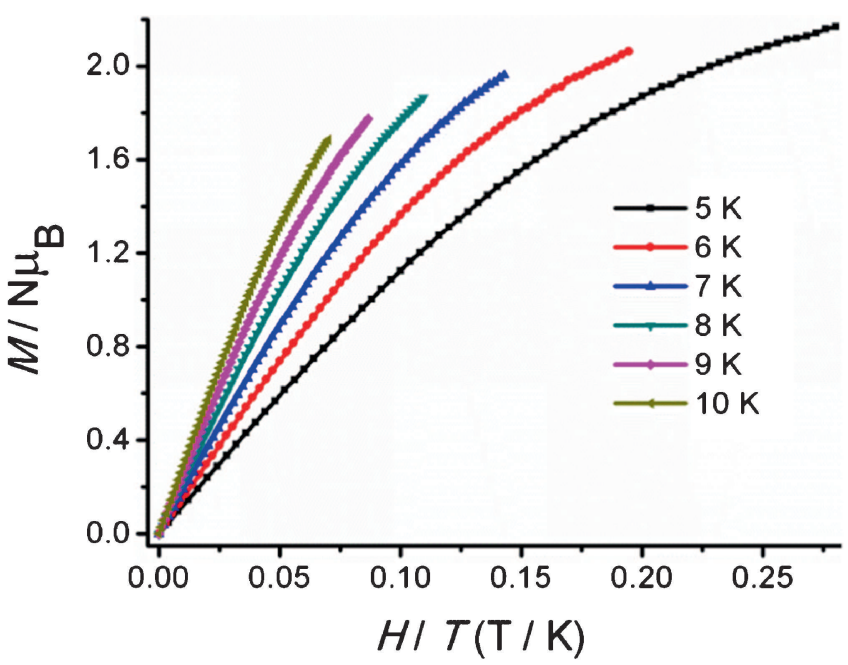

Figure 9. $\mathrm{M} / N \mu_{\mathrm{B}} v s . \mathrm{H} / \mathrm{T}$ plots for complex 1 measured at $5-10 \mathrm{~K}$.

the exchange parameters could not be estimated. The isothermal magnetization curve $\left(M / N \mu_{\mathrm{B}} v s . H\right.$ plot, figure 8) shows a value of $2.33 N \mu_{\mathrm{B}}$ per formula unit at $2 \mathrm{~K}$ and $7 \mathrm{~T}$, lower than the saturation value of $3 N \mu_{\mathrm{B}}$ for the spin-onlyCo(II) ion $(\mathrm{S}=3 / 2 \text { and } \mathrm{g}=2)^{16}$ which is usual for octahedral high-spin $\mathrm{Co}$ (II) ions in low temperature range. It was also observed that $M / N \mu_{\mathrm{B}}$ vs. $H / T$ curves did not superimpose (figure 9), giving the indication of anisotropy, so the ac magnetization dynamics was studied as a function of temperature and frequency in zero and higher dc fields and 3.5 Oe ac field. But no ac signals were obtained, which is likely due to small energy barrier or quantum tunnelling of magnetization (QTM) which ruled out the possibility of single molecular magnetic (SMM) behaviour of the complex.

\section{Conclusion}

We have reported here the synthesis and characterization of a novel Co(II)-based 3D framework. The complex is formed of two-dimensional grid-like network which showed inclined interpenetration with other 2D networks giving rise to $2 \mathrm{D} \rightarrow 3 \mathrm{D}$ inclined polycatenation with sql/Shubnikov tetragonal plane net topology. Structural investigation also revealed extensive non-covalent interactions (H-bonding as well as $\pi \cdots \pi$ interactions) which gave stability to the 3D arrangement and 1D channels of large dimensions $(10.91 \times$ $11.78 \AA^{2}$ ) running along the $b$-axis. Variable temperature DC magnetic susceptibility study exhibited dominant spin-orbit coupling effect typical of the octahedral high-spin $\mathrm{Co}(\mathrm{II})$ ion at higher temperature range. 


\section{Supplementary Information}

TGA profiles and PXRD spectra (figures S4 and S5) can be seen at www.ias.ac.in/chemsci as supplementary information. CCDC-1026263 contains the supplementary crystallographic data for this paper. These data can be obtained free of charge from The Cambridge Crystallographic Data Center via www.ccdc.cam.ac.uk/ data_request/cif.

\section{Acknowledgement}

SG is thankful to IISER Bhopal for SRF fellowship and AKM thanks UGC, India for JRF fellowship. SK thanks CSIR, India (Project No. 01/2473/11/EMRII) and IISER Bhopal for generous financial and infrastructural support.

\section{References}

1. (a) Kitaura R, Kitagawa S, Kubota Y, Kobayashi T C, Kindo K, Mita Y, Matsuo A, Kobayashi M, Chang H-C, Ozawa T C, Suzuki M, Sakata M and Takata M 2002 Science 298 2358; (b) Li H, Eddaoudi M, OKeeffe M and Yaghi O M 1999 Nature 402 276; (c) Zhao X, Xiao B, Fletcher J A, Thomas K M, Bradshaw D and Rosseinsky M J 2004 Science 306 1012; (d) Ferey G, Mellot-Draznieks C, Serre C, Millange F, Dutour J, Surble S and Margiolaki I 2005 Science 309 2040; (e) Ganguly S, Pachfule P, Bala S, Goswami A, Bhattacharya S and Mondal R 2013 Inorg. Chem. 52 3588; (f) Chandler B D, Enright G D, Udachin K A, Pawsey S, Ripmeester J A, Cramb D T and Shimizu G K H 2008 Nat. Mater. 7 229; (g) Murray L J, Dinca M and Long J R 2009 Chem. Soc. Rev. 38 1294; (h) Khatua S, Goswami S, Parshamoni S, Jena H S and Konar S 2013 RSC Advances 3 25237; (i) Sanda S, Parshamoni S, Adhikary A and KonarS 2013 Cryst. Growth Des. 13 544; (j) Biswas S, Jena H S, Goswami S, Sanda S and Konar S 2014 Cryst. Growth Des. 141287

2. (a) Gatteschi D, Sessoli R and Villain J 2006 Molecular Nanomagnets; Oxford University Press: New York; (b) Kahn O 1993Molecular Magnetism, New York: VCH publishers, (c) Kurmoo M 2009Chem. Soc. Rev. 38 1353; (d) Ohkoshi S, Arai K, Sato Y and Hashimoto K 2004 Nat. Mater. 3 857; (e) Miller J S 2011 Chem. Soc. Rev. 40 3266; (f) Dechambenoit P and Long J R 2011 Chem. Soc. Rev. 40 3249; (g) Tasiopoulos A J, Vinslava A, Wernsdorfer W, Abboud K A and Christou G 2004 Angew. Chem., Int. Ed. 43 2117; (h) Goswami S, Adhikary A, Jena H S, Biswas S and Konar S 2013 Inorg. Chem. 52 12064; (i) Goswami S, Sanda S and Konar S 2014 Cryst. Eng. Comm. 16 369; (j) Biswas S, Adhikary A, Goswami S and Konar S 2013 Dalton Trans. 42 13331; (k) Goswami S, Adhikary A, Jena H S and Konar S 2013 Dalton Trans. 42 9813; (1) Hu S, Yun L, Zheng Y-Z, Lan Y-H, Powell A K and Tong M-L 2009 Dalton Trans. 1897; (m) Mukherjee S, Lan Y,
Kostakis G E, Clerac R, Anson C E and Powell A K 2009 Cryst. Growth Des. 9 577; (n) Giles I D, Chifotides H T, Shatruk M and Dunbar K R 2011 Chem. Commun. 47 12604; (o) Smith T M, Tichenor M, Zhang Y-Z, Dunbar K R and Zubieta J 2014 Dalton Trans. 43 7263

3. (a) Alkordi M H, Liu Y, Larsen R W, Eubank J F and Eddaoudi M 2008 J. Am. Chem. Soc. 130 12639; (b) Goswami S, Jena H S and Konar S 2014 Inorg. Chem. 53 7071; (c) Parshamoni S, Sanda S,Jena H S and Konar S 2014 Dalton Trans. 43 7191; (d) Lee J Y, Farha O K, Roberts J, Scheidt K A, Nguyen S T and Hupp J T 2009 Chem. Soc. Rev. 38 1450; (e) Seo J S, Whang D, Lee H, Jun S I, Oh J, Jeon Y J and Kim K 2000 Nature 404 982; (f) Zou R-Q, Sakurai H and Xu Q 2006 Angew. Chem. Int. Ed. 452542

4. (a) Farha O K and Hupp J T 2010 Acc. Chem. Res. 43 1166; (b) Horcajada P, Serre C, Vallet-Regi M, Sebban M, Taulelle F and Ferey G 2006 Angew. Chem. Int. Ed. 45 5974; (c) Rocca J D, Liu D and Lin W 2011 Acc. Chem. Res. 44957 and references cited therein

5. (a) Kreno L E, Leong K, Farha O K, Allendorf M, Van Duyne R P and Hupp J T 2012 Chem. Rev. 1121105 and references cited therein; (b) Cui Y, Yue Y, Qian G and Chen B 2012 Chem. Rev. 1121126 and references cited therein

6. (a) OKeeffe M, Peskov M A, Ramsden S J and Yaghi O M 2008 Acc. Chem. Res. 41 1782; (b) Hou Y L, Xiong G, Shi P F, Cheng R R, Cui J Z and Zhao B 2013 Chem. Commun. 49 6066; (c) Tan C, Yang S, Champness N R, Lin X, Blake A J, Lewis W and Schröder M 2011 Chem. Commun. 47 4487; (e) Wu H; Yang J, Su Z-M, Batten S R, Ma J-F 2011 J. Am. Chem. Soc. 133, 11406. (f) Zha Q, Ding C, Rui X and Xie Y 2013 Cryst. Growth Des. 13 4583; (g) Nagarkar S S, Chaudhari A K and Ghosh S K 2011 Inorg. Chem. 51572

7. (a) Shimomura S, Yanai N, Matsuda R and Kitagawa S 2011 Inorg. Chem. 50 172; (b) Zhao J P, Han S D, Zhao R, Yang Q, Chang Z and Bu X H 2013 Inorg. Chem. 52 2862; (c) Banerjee S, Adarsh N N and Dastidar P 2012 Cryst. Growth Des. 12 6061; (d) Zang S-Q, Dong M-M, Fan Y-J, Hou H-W and Mak T C W 2012 Cryst. Growth Des. 12 1239; (e) Chen M, Chen S-S, Okamura T, Su Z, Chen M-S, Zhao Y, Sun W-Y and Ueyama N 2011 Cryst. Growth Des. 111901

8. (a) Masoomi M Y, Stylianou K C, Morsali A, Retailleau P and Maspoch D 2014 Cryst. Growth Des. 14 2092; (b) Bhattacharya B, Haldar R, Dey R, Maji T K and Ghoshal D 2014 Dalton Trans. 43 2272; (c) Hu F-L, Mi Y, Gu Y-Q, Zhu L-G, Yang S-L, Wei H and Lang J-P 2013 Cryst. Eng. Comm. 15 9553; (d) Hu F, Zou H, Zhao X, Mi Y, Luo C and Wang Y 2013 Cryst. Eng. Comm. 15 1068; (e) Yang J-X, Qin Y-Y, Cheng J-K and Yao Y-G 2014 Cryst. Growth Des. 141047

9. (a) Ahmad M, Das R, Lama P, Poddar P and Bharadwaj P K 2012 Cryst. Growth Des. 12 4624; (b) Dong M-M, He L-L, Fan Y-J, Zang S-Q, Hou H-W and Mak T C W 2013 Cryst. Growth Des. 13 3353; (d) Ma L F, Han M L, Qin J H, Wang L Y and Du M 2012 Inorg. Chem. 51 9431; (e) Sengupta S, Ganguly S, Goswami A, Bala S, Bhattacharya S and Mondal R 2012 CrystEngComm 14 7428; (g) Zhang L, Yao Y-L, Che Y-X and Zheng J-M 
2010 Cryst. Growth Des. 10 528; (h) Sun D, Yan Z-H, Blatov V A, Wang L and Sun D-F 2013 Cryst. Growth Des. 131277

10. (b) Gao E-Q, Cheng A-L, Xu Y-X, He M-Y and Yan C-H 2005 Inorg. Chem. 44 8822; (c) Zhao Q H, Liu Y Q and Fang R B 2006 Inorg. Chem. Commun. 9 699; (d) Zhang G, Yang G and Ma J S 2006 Cryst. Growth Des. 6 1897; (e) Ghoreishi Amiri M, Mahmoudi G, Morsali A, Hunter A D and Zeller M 2007 Cryst. Eng. Comm. 9 686; (f) Wang C-C, Lin W-Z, Huang W-T, Ko M-J, Lee G-H, Ho M-L, Lin C-W, Shih C-W and Chou P-T 2008 Chem. Commun. 1299; (g) Mukherjee A, Chakrabarty R and Patra G K 2009 Inorg. Chem. Commun. 121227

11. Sheldrick G 1997 SHELXL-97, Program for Crystal Structure Refinement; University of Gottingen: Gottingen, Germany

12. Farrugia L J 1999 J. Appl. Crystallogr. 32837

13. (a) Blatov V A, Shevchenko A P and Serezhkin V N 2000 J. Appl. Crystallogr. 33 1193; (b) Blatov V A 2006 IUCr CompComm Newsletter 7 4-38. In inorganic and organic-inorganic hybrid material chemistry with extended framework structures like zeolites, coordination polymers (CPs), Metal Organic Frameworks (MOFs) etc. a strong correlation exists between the coordination type of ligand, coordination number of central metal atom and the global topology of the net. So, analysis of periodic structures (nets, tilings, surfaces, etc.) and describing the topological aspects is a very important task. In this context, TOPOS software is a very important tool which is applied to obtain simplified representations of the structural groups as nets, where the nodes correspond to metals and/or centers of gravity of multidentate ligands. In this paper, using TOPOS we observed that our 3D framework structure represents a 4-connected uninodal framework with sql/Shubnikov tetragonal plane net topology and point Schälfli symbol $\left\{4^{4} \cdot 6^{2}\right\}$

14. (a) Batten S R 2001 CrystEngComm 3 67-72; (b) Carlucci L, Ciani G and Proserpio D M 2003 Coord. Chem.Rev. 246 247-289

15. Spek A L 2003 J. Appl. Crystallogr. 367

16. (a) Laget V, Hornick C, Rabu P, Drillon $M$ and Ziessel R 1998 Coord. Chem. Rev. 178-180 1533 and references cited therein; (b) Mabbs F E and Machin D J 1973 Magnetism in Transition Metal Complexes, Chapman and Hall, London; (c) Nagaraja C M, Kumar N, Maji T K and Rao C N R 2011 Eur. J. Inorg. Chem. 2057; (d) Wang X Y, Gan L, Zhang S W and Gao S 2004 Inorg. Chem. 434615 